\title{
Exploration of in vivo efficacy of artemether- lumefantrine against uncomplicated Plasmodium falciparum malaria in under fives in Tabora region, Tanzania
}

\author{
Deokary Joseph ${ }^{1,3}$, Abdunoor M Kabanywanyi ${ }^{2}$, Ruth Hulser ${ }^{3}$, Zulfiqarali Premji ${ }^{4}$, Omary MS Minzi ${ }^{4}$ \\ and Kefas Mugittu ${ }^{5^{*}}$
}

\begin{abstract}
Background: Tanzania adopted artemether-lumefantrine (AL) as first-line drug for uncomplicated malaria in 2006. Recently, there was an anecdotal report on high malaria recurrence rate following AL treatment in in the (urban and peri-urban), western part of Tanzania. The current report is an exploratory study to carefully and systematically assess AL efficacy in the area.

Methods: Between June and August 2011, a total of 1,126 patients were screened for malaria, 33 had malaria, of which 20 patients met inclusion criteria and were enrolled and treated with standard dose of AL as recommended in the WHO protocol. Treated patients were followed up for 28 days to assess treatment responses. Before treatment (Day 0) and post-treatment (Day 7) plasma lumefantrine levels were determined to assess prior AL use and ascertain parasites exposure to adequate plasma leveles of lumefantrine, respectively.

Results: The cure rate was 100\%. All Day 0 plasma lumefantrine were below HPLC detectable level. The median Day 7 lumefantrine concentration was 404, (range, 189-894 ng/ml). Six out of 20 patients (30\%) were gametocytaemic and all cleared gametocytes by Day 14 . One patient showed an increase in gametocytes from four on Day 0 to 68, per 500 WBC on Day 2.

Conclusion: Artemether lumefantrine is highly efficacious against uncomplicated Plasmodium falciparum malaria. The elevation of gametocytaemia despite AL treatment needs to be evaluated in a larger study.
\end{abstract}

\section{Background}

The adoption of artemisinin-based combination therapy (ACT) in sub-Saharan Africa as first-line drug for the treatment of uncomplicated malaria [1] was largely based on experience gained in low transmission areas of Southeast Asia using artesunate-mefloquine (AS-MQ) [2]. The few studies conducted in sub-Saharan Africa prior to adoption of AS+AQ and AL recorded nearly 100\% cure rate $[3,4]$. However, the long-term impact and extended useful therapeutic life of these drug combinations in high transmission areas remains unclear. Already increased parasite clearance half-life and reduced susceptibility to

\footnotetext{
* Correspondence: kmugittu@ihi.or.tz

5 Ifakara Health Institute, PO Box 74, Bagamoyo, Tanzania

Full list of author information is available at the end of the article
}

artemisinins and artesunate-mefloquine has been reported in Thai-Cambodia and Thai-Myanmar boarder $[5,6]$. Indeed there is now both phenotypic [7] and genetic [8] evidence of artemisinin resistance in these areas. It is hypothesized that if not controlled, artemisinin resistance might eventually spread all over the malaria-endemic world. Thus WHO recommends increased monitoring and surveillance to evaluate the threat of artemisinin resistance and identify new foci rapidly and to provide information for immediate and comprehensive containment and prevention activities. Therefore, this exploratory study was carried out as an action plan in response to reports of high recurrent rate following AL treatment in Tabora, western Tanzania (pers comm, Dr Ruth Hulser, St Phillip's 
Health Centre, Tabora) in order to rule out possibility of $\mathrm{AL}$ resistance in the region.

\section{Methods}

Study site, design, sampling frame and sample size

An in vivo study was carried out between mid-June and mid-August 2011 at Kitete Regional Hospital and St. Philip's and St Anne's health facilities serving the urban and peri-urban areas of Tabora municipality. Tabora is a high-burden area and malaria transmission peaks during the rain season, i.e., February to May [9]. Children aged six to 59 months reporting to the hospital with fever or history of fever underwent physical and clinical examination by the study clinician. Inclusion and exclusion criteria are as described in the WHO protocol for high transmission areas [10]. The recruited patients were treated under supervision with a standard six doses of dispersible formulation of AL (Coartem ${ }^{\circledR}$, Novartis) with full cream milk. The first dose was given at the health centre by a study nurse or clinician and the subsequent doses were given at home by a parent or guardian and monitored by study personnel through mobile phone call or home visits if the parent/guardian was not reachable by mobile phone. Three children vomited within 30 min of first dose and replacement dose was given and no patient vomited a replaced dose.

The clinical and parasitological responses were assessed on Day 2, 3, 7, 14, 21 and 28 during the 28-day follow-up period. Parasitological responses were assessed microscopically by counting against 200 or 500 white blood cells for asexual and sexual (gametocytes), respectively. Gametocytes were not staged. Admittedly, one major limitation is that microscopy understimates the prevalence of gametocytes. Plasma lumefantrine levels were determined before treatment (Day 0) and post-treatment (Day 7). In the three months, of 1,126 children screened 33 had malaria and only 20 met the inclusion criteria and were recruited (Figure 1), following the recommendations of at least 12 patients per treatment for an exploratory study [11]. The primary efficacy endpoints were classified as: early treatment failure (ETF), late clinical failure (LCF), late parasitological failure (LPF) and adequate clinical and parasitological response (ACPR) on 28 days' follow-up period [12]. There was no loss to follow up despite the fact that some patients came as far as $10 \mathrm{~km}$ away from the health facilities.

\section{Determination of plasma lumefantrine levels}

From each recruited patient, $2 \mathrm{ml}$ venous blood was collected into heparinized vacutainers on Day 0 and Day 7 for plasma drug level determination. The plasma was separated from blood cells by centrifugation, transferred into $2 \mathrm{ml}$ cryovials and stored in liquid nitrogen. All plasma samples were sent to Muhimbili University College



of Health and Allied Sciences (MUHAS) laboratory for lumefantrine level analysis by high performance liquid chromatographic (HPLC) method as described [12].

The study protocol was reviewed and approved by Ethical Review Committee of the Ifakara Health Institute (IHI) and MUHAS. Prior to the trial, a written consent form was signed by the parent or guardian of each participating child.

\section{Results}

\section{Study profile and treatment outcome}

A total number of 1,126 patients were screened from the three health facilities in Tabora region as follows: St Philip's Health Centre: $n=663$; St Anne's Health Centre: $\mathrm{n}=345$; and, Kitete Regional Hospital: $\mathrm{n}=118$. The baseline characteristics of the study participants are indicated in Table 1.

Twenty-four (24) out of 663 (3.6\%), five out of 345 (1.4\%) and four out of 118 (3.4\%) patients in St Phillip's, St Anne's Health Centres and Ketete Hospital, respectively, were positive for malaria parasites by microscopy. Comparison of routine (before the study) and expert (during the study) malaria diagnosis was done. The routine and expert malaria microscopy results recorded in

Table 1 Baseline characteristics of the study participants

\begin{tabular}{llllll}
\hline & $\mathbf{n}$ & Minimum & Maximum & Mean & Std Deviation \\
\hline Age (months) & 20 & 6.00 & 59.00 & 39.3500 & 18.65 \\
\hline Weight $(\mathrm{Kg})$ & 20 & 6.7 & 23.4 & 14.9 & 4.5 \\
\hline Temp $\left({ }^{\circ} \mathrm{C}\right)$ & 20 & 35.3 & 39.7 & 37.8 & 1.4 \\
\hline Par. $/ 200 \mathrm{wbc}$ & 20 & 56 & 3577 & 985 & 986 \\
\hline Parasites $/ \mu \mathrm{l}$ & 20 & 2240 & 143,080 & 39,400 & 39450 \\
\hline $\mathrm{Hb}(\mathrm{g} / \mathrm{dl})$ & 20 & 6.3 & 12.9 & 9.1 & 1.7 \\
\hline
\end{tabular}


Table 2 Haemoglobin levels on Day 0 and Day 7

\begin{tabular}{llllll}
\hline & N & Minimum & Maximum & Mean & Std Deviation \\
\hline Day 0 Hb(in g/dl) & 20 & 6.30 & 12.9 & 9.14 & 1.69 \\
\hline Day $7 \mathrm{Hb}(\mathrm{g} / \mathrm{dl})$ & 20 & 6.90 & 12.70 & 9.64 & 1.62 \\
\hline
\end{tabular}

the first (50.3\% positive $n=163$ ) and second half $(5.1 \%$ positive $n=176$ ) of June 2011, respectively, were significantly different $(\mathrm{p}<0.005)$. Only 20 patients met the inclusion criteria and were enrolled. Patients were treated and assessed for treatment outcome without loss of follow up as detailed in Figure 1. The cure rate of the drug was $100 \%$. Table 2 shows that the mean haemoglobin was significantly increased, from $9.1( \pm 1.69) \mathrm{g} / \mathrm{dL}$ on Day 0 to $9.6 \mathrm{~g} / \mathrm{dL}( \pm 1.62)$ on Day $7(\mathrm{p}=0.048)$.

\section{Plasma lumefantrine levels of patients}

The lumefantrine plasma concentrations measured in patients before drug administration in all 20 enrolled patients were below HPLC detection level. The median Day 7 lumefantrine concentration level was $404.4 \mathrm{ng} / \mathrm{ml}$ (range 189.4-894.3 ng/ml). Only four (20\%) patients had lumefantrine plasma concentration level $<280 \mathrm{ng} / \mathrm{ml}$, and no patient had lumefantrine plasma concentration level $<175 \mathrm{ng} / \mathrm{ml}$. Lumefantrine concentration at day 7 was slightly decreased with unit increase in weight $(\mathrm{kg})$ for any age but this decrease was not statistically significant $(\mathrm{p}$-value $=0.445)$.

\section{Gametocyte prevalence}

Table 3 shows gametocytaemia before and after AL treatment. Six of the 20 patients (30\%) had gametocytes under microscopic observation on Day 0 and all were above 36 months of age. In five patients the gametocytes persisted up to Day 7 after treatment and one patient had gametocytes up to Day 14 and one had gametoctes only on Day 0 . One patient showed an increase in gametocytes after treatment from four gametocytes per $500 \mathrm{WBC}$ on Day 0 to 68 gametocytes per 500 WBC on Day 2 followed by a decrease on subsequent days after treatment. No gametocytes were seen microscopically after Day 14 .

\section{Discussion}

Artemisinins are known to be highly potent anti-malarial drugs that are active against immature gametocytes $[13,14]$, hence pivotal in reduction of malaria transmission and elimination/eradication agenda. To the best of authors' knowledge, there is no evidence of clinical resistance to AL. However tolerance or increased parasite clearence time and reduced susceptibility to artemisinins and artesunate-mefloquine has been observed in Thai-Cambodia and Thai-Mynmar boarder $[5,6]$. This is the same locus where chloroquine resistance first emerged and subsequently spread all over the world. Emergence of artermisinin resistance would be disastrous for global malaria control. Therefore, regular surveillance and prompt response to any indication of compromised efficacy is required [15].

This study recorded high (100\%) efficacy of AL. The reported efficacy level is more or less similar to $>98 \%$ recorded in Tanzania, prior to introduction of AL [4], and elsewere in Africa [16-20]. However, in these other studies, the high efficacy rates were reached after exclusion of new infection by molecular genotyping. Therefore, it is obvious that the cause of alarm that prompted this exploratory study in Tabora was not malaria recurrence or compromised AL efficacy but malaria overdiagnosis. This practice has been reported previously elsewhere in Africa [21,22] as a cause of inappropriate malaria case managment [23]. Overdiagnosis is attributable to incompetency of laboratory workers, work overload, and pressure from patients with fever accepting malaria diagnosis [21].

In this study, none of the patients reported to have taken AL prior to hospital presentation, which was confirmed by lack of lumefantrine traces in the plasma. In addition, all patients had adequate therapautic levels of lumefantrine on Day 7. However, the Day 7 plasma lumefantrine levels showed wide variation between individuals. Indeed, it is known that the efficacy of AL combination is strongly influenced by wide variation in the pharmacokinetics of lumefantrine among individuals [24]. The maximum therapeutic cure rate is achieved when the plasma drug concentration is adequately available for at least three parasite life cycles that is equal to

Table 3 Presence of gametocytes in six children by time

\begin{tabular}{lllllllll}
\hline $\begin{array}{l}\text { Patient } \\
\text { (ID) }\end{array}$ & $\begin{array}{l}\text { Age } \\
\text { (months) }\end{array}$ & Day $\mathbf{0}$ & Day 2 & Day3 & Day 7 & D ay 14 & Day 21 & Day 28 \\
\hline 1 & 59 & 7 & 0 & 0 & 0 & 0 & 0 \\
\hline 3 & 48 & 4 & 68 & 43 & 5 & 0 & 0 & 0 \\
\hline 4 & 59 & 145 & 123 & 85 & 28 & 0 & 0 \\
\hline 10 & 50 & 6 & 4 & 5 & 2 & 0 & 0 \\
\hline 16 & 36 & 13 & 10 & 7 & 4 & 0 & 0 \\
\hline 20 & 59 & 11 & 3 & 2 & 2 & 2 & 0 & 0 \\
\hline
\end{tabular}


six days [25]. The impact of pharmacokinetic variation on selection for resistance to residual parasites in high transmission areas needs to be carefully evaluated.

Artemether-lumefantrine showed short fever and parasites clearence time and quick recovery of haemoglobin levels. Only one patient had fever up to Day 1 and neither fever nor parasitaemia was reported on Day 2, contrary to a report in central Ethiopia where fever and parasitaemia persisted to Day 3 [26]. Haemoglobin levels significantly increased on Day 7 as reported in other studies in this region, but the second haemoglobin measurement was done on Day $14[27,28]$. The complete 28 days' follow up to all patients was achieved by using mobile phone calls to remind parents or guardians about their appointment dates and days. Mobile phone contacts might minimize loss to follow up in efficacy studies.

The Day 0 gametocyte prevalence $(30 \%)$ recorded in this study is higher compared with those reported previously in Tanzania $[29,30]$. Furthermore, as observed elsewhere in Africa [27,31-33], no new gametocytaemic cases were observed during the follow-up period. Admittedly, this could be attributable to small sample size, which is a limitation of this study, and microscopy detection limit. Gametocytaemia persisted for seven to 14 days, (as recorded previously), against 55 days for non-ACT drugs [34].

ACT is effective against immature sequestered gametocytes $[32,34,35]$, hence they reduce gametocyte carriage as well as gametocytes density [31,36,37]. Apparently, ACT does not affect the viability of mature gametocytes $[31,36]$. Consequently, persistence of mature gametocytes might still play a role on maintianing transmission cycle. Hence, combination with a strong gametocytocidal drug such as primaquine will maximize $\mathrm{ACT}$ usefulness.

The phenomenon of increase in gametocytaemia in this study and of sexual stage count in Nigeria [38] despite drug treatment, might be a sign of tolerance or emergence of parasites with reduced drug sensitivity in the region. Another plausible explanation for the increase in gametocytaemia is coincidence between drug administration and maturation release of mature gametocytes into the peripheral circulation. These observations of increased gametocytaemia after treatment need to be verified in a larger study.

\section{Conclusion}

The therapeutic efficacy of AL against uncomplicated $P$. falciparum malaria was high in the study area. All patients were not exposed to AL prior to hospital presentation and levels of lumefantrine on Day 7 were therapeutically adequate but highly variable. The unusual increase in gametocytes following treatment needs be evaluated in a larger study concurrent with improvement capacity to diagnose malaria and handling of nonmalarial fevers.

\section{Competing interests}

The authors declare that they have no competing interests.

\section{Authors' contributions}

KM, AM and ZP designed the study. KM and DJ supervised the field work. SA and AMK and ZP supervised the clinical part. MOMS supervised the drug level analysis and pharmacokinetics. DJ was involved in drug analysis and analysed data. RH is the in charge of St Philip's Health Centre. DJ and KM wrote the manuscript. All authors read and approved the final manuscript.

\section{Acknowledgements}

The study team is thankful to parents/guardians of all children who volunteered and consented to participate in this study. Our field team and health workers at St Philip's, St Anne's Health Centres and Kitete-Tabora Regional Hospital are highly appreciated. The authors are grateful to the MUHAS - Sida Bioanalytical laboratory colleagues who were involved in drug levels analysis. This study was part of Deokari Joseph's MSc project which was jointly sponsored by Ifakara Health Institute $(I H I)$, Dar Es Salaam University College of Education (DUCE), and Muhimbili Uniniversity of Health and Allied Science.

\section{Author details}

'Dar es Salaam University College of Education, PO Box 2329, Dar es Salaam, Tanzania. ${ }^{2}$ Ifakara Health Institute, PO Box 78373, Dar es Salaam, Tanzania. ${ }^{3} \mathrm{St}$ Phillip's Health Centre, PO Box 1408, Tabora, Tanzania. ${ }^{4}$ Muhimbili University of Health and Allied Sciences, PO Box 65001, Dar es Salaam, Tanzania.

${ }^{5}$ Ifakara Health Institute, PO Box 74, Bagamoyo, Tanzania.

Received: 9 November 2012 Accepted: 5 February 2013

Published: 11 February 2013

\section{References}

1. WHO: Guidelines for Malaria Treatment. Geneva: World Health Organization; 2006. http://whqlibdoc.who.int/publications/2006/9241546948_eng.pdf.

2. Bloland PB, Ettling M, Meek S: Combination therapy for malaria in Africa: hype or hope? Bull World Health Organ 2000, 78:1378-1388.

3. Adjuik MA, Babiker A, Garner P, Olliaro P, Taylor W, White N: Artesunate combinations for treatment of malaria: meta analysis. Lancet 2004 , 363:9-17.

4. Kabanywanyi AM, Mwita A, Sumari D, Mandike R, Mugittu K, Abdulla S: Efficacy and safety of artemisinin-based antimalarial in the treatment of uncomplicated malaria in children in southern Tanzania. Malar J 2007, 6:146.

5. Noedl $H$, Socheat $D$, Satimai W: Artemisinin-resistant malaria in Asia. NEJM 2009, 361:540-541.

6. Na-Bangchang K, Ruengweerayut R, Mahamad P, Ruenweerayut K, Chaijaroenkul W: Declining in efficacy of athree-day combination regimenof mefloquine-artesunate in multidrug resistance area alon the Thai-Mynmar Border. Malar J 2010, 9:273.

7. Dondorp AM, Nosten F, Yi P, Das D, Phyo AP, Tarning J, Lwin KM, Ariey F, Hanpithakpong W, Lee SJ, Ringwald P, Silamut K, Imwong M, Chotivanich K, Lim P, Herdman T, An SS, Yeung S, Singhasivanon P, Day NP, Lindegardh N, Socheat D, White NJ: Artemisinin resistance in Plasmodium falciparum malaria. N Engl J Med 2009, 361:455-467.

8. Cheeseman IH, Miller BA, Nair S, Nkhoma S, Tan A, Tan JC, Al Saai S, Phyo AP, Moo CL, Lwin KM, McGready R, Ashley E, Imwong M, Stepniewska K, Yi P, Dondorp AM, Mayxay M, Newton PN, White NJ, Nosten F, Ferdig MT, Anderson TJ: A major genome region underlying artemisinin resistance in malaria. Science 2012, 336:79-82.

9. Mazigo HD, Meza W, Ambrose EE, Kidenya BR, Kweka EJ: Confirmed malaria cases among children underfive with fever and history of fever in rural western Tanzania. BMC Research Notes 2011, 4:359.

10. WHO: Methods for Surveillance of Antimalarial Drug Efficacy. Geneva: World Health Organization; 2009.

11. Julious S: Sample size of 12 per group rule of thumb for a pilot study. Pharm Stat 2005, 4:287-291.

12. Minzi OMS, Sasi P, Mareale I: Interlaboratory development and cross validation of a chromatographic method for determination of 
lumefantrine in human plasma - a proficient capacity assessment of bioanalytical laboratories in East. J Anal Bioanal Techniques 2012, 3:2.

13. Nosten F, Luxemburger C, ter Kuile FO, Woodrow C, Eh JP, Chongsuphajaisiddhi T, White NJ: Treatment of multidrug-resistant Plasmodium falciparum malaria with 3-day artesunate-mefloquine combination. J Infect Dis 1994, 170:971-977.

14. Price RN, Nosten F, Luxemburger C, ter Kuile FO, Paiphun L, Chongsuphajaisiddhi T, White NJ: Effects of artemisinin derivatives on malaria transmissibility. Lancet 1996, 347:1654-1658.

15. WHO: Global Plan for Artemisinin Resistance Containment (GPARC. Geneva, Switzerland: World Health Organization; 2011. http:/wwww.who.int/malaria/ publications/atoz/artemisinin_resistance_containment_2011.pdf.

16. Guthmann J-P, Cohuet S, Rigutto C, Fortes F, Saraiva N, Kiguli J, Kyomuhendo J, Francis M, Noel F, Mulemba M, Balkan S: High efficacy of two artemisinin-based combinations (artesunate + amodiaquine and artemether + lumefantrine) in Caala, Central Angola. AmJTrop Med Hyg 2006, 75:143-145.

17. van den Broek I, Kitz C, Attas SA, Libama F, Balasegaram M, Guthmann JP: Efficacy of three artemisinin combination therapies for the treatment of uncomplicated Plasmodium falciparum malaria in the Republic of Congo. Malar J 2006, 5:113.

18. Thapa S, Hollander J, Linehan M, Cox-Singh J, Bista MB, Thakur GD, Davis WAand Davis TME: Comparison of artemether-lumefantrine with sulfadoxine-pyrimethamine for the treatment of uncomplicated falciparum malaria in Eastern Nepal. AmJTrop Med Hyg 2007, 77:423--430.

19. Faye B, Ndiaye J-L, Ndiaye D, Dieng Y, Faye O, Gaye O: Efficacy and tolerability of four antimalarial combinations in the treatment of uncomplicated Plasmodium falciparum malaria in Senegal. Malar J 2007, 6:80

20. Falade CO, Ogundele AO, Yusuf BO, Ademowo OG, Ladipo SM: High efficacy of two artemisinin-based combinations (artemether-lumefantrine and artesunate plus amodiaquine) for acute uncomplicated malaria in Ibadan, Nigeria. Trop Med Int Health 2008, 13:635-643.

21. Chandler CIR, Jones C, Boniface G, Juma K, Reyburn H, Whitty CJM: Guidelines and mindlines: why do clinical staffs over-diagnose malaria in Tanzania?A qualitative study. Malar J 2008, 7:53.

22. Nankabirwa J, Zurovac D, Njogu JN, Rwakimari JB, Counihan H, Snow RW, Tibenderana JK: Malaria misdiagnosis in Uganda - implications for policy change. Malar J 2009, 8:66.

23. Schoepflin S, Lin E, Kiniboro B, DaRe JT, Mehlotra RK, Zimmerman PA, Mueller I, Felger I: Treatment with Coartem (Artemether-Lumefantrine) in Papua New Guinea. AmJTrop Med Hyg 2010, 82:529-534.

24. WHO: Guidelines for the Treatment of Malaria. secondth edition. Geneva, Switzerland: World Health Organization; 2010.

25. White NJ: Preventing antimalarial drug resistance through combinations. Drug Resist Updat 1998, 1:3-9.

26. Hwang J, Alemayehu BH, Hoos D, Melaku Z, Tekleyohannes SG, Teshi T, Birhanu SG, Demeke L, Gobena K, Kassa M, Jima D, Reithinger R, Nettey H, Green M, Malone JL, Kachur SP, Filler S: In vivo efficacy of artemetherlumefantrine against uncomplicated Plasmodium falciparum malaria in Central Ethiopia. Malar J 2011, 10:209.

27. Hatz C, Abdulla S, Mull R, Schellenberg D, Gathmann I, Kibatala P, Beck HP, Tanner MRC: Efficacy and safety of CGP56697(artemether andn benflumetol) compared with chloroquine to treat acute falciparum malaria inTanzania children aged $1-5$ years. Trop Med Int Health 1998, 3:498-504.

28. Assefa A, Kassa M, Tadese G, Mohamed H, Animut A, Mengesha T: Therapeutic efficacy of artemether/lumefantrine $\left(\right.$ Coartem $\left.{ }^{\circledR}\right)$ against Plasmodium falciparum inKersa, South West Ethiopia. Parasit Vectors 2010, 3:1.

29. Akim JIN, Drakeley C, Kingo TB, Senkoro K, Sauerwein RW: Dynamics of P. falciparum gametocytemia in symptomatic patients in an area of intense perennial transmission in Tanzania. AmJTrop Med Hyg 2000, 63:199-203.

30. Price RN, Uhlemann $A C$, van Vugt $M$, Brockman A, Hutagalung $R$, Nair $S$, Nash D, Singhasivanon P, Anderson TJ, Krishna S, White NJ, Nosten F: Molecular and pharmacological determinants of the therapeutic response to artemether-lumefantrine in multidrug-resistant Plasmodium falciparum malaria. Clin Infect Dis 2006, 42:1570-1577.

31. Bousema JT, Schneider P, Gouagna LC, Drakeley Chris J, Tostmann A, Houben R, Githure Ord R, Sutherland CJ, Omar SA, Sauerwein RW:
Moderate effect of artemisinin-based combination therapy on transmission of Plasmodium falciparum. J Infect Dis 2006, 193:1151-9.

32. Southerland CJ, Ord R, Dunyo S, Jawara M, Drakeley CJ, Alexander N, Coleman R, Pinder M, Walraven G, Targett GAT: Reduction of malaria transmission to anopheles mosquitoes with a six-dose regimen of co-artemether. PLoS Med 2005, 2:e92.

33. Barnes Kl, Chanda P, Barnabas G: Impact of the large-scale deployment of artemether/lumefantrine on the malaria disease burden in Africa: case studies of South Africa, Zambia and Ethiopia. Malar J 2009, 8(1):S8.

34. Bousema T, Okell L, Shekalaghe S, Griffin JT, Omar S, Sawa P, Sutherland C, Sauerwein R, Ghani AC, Drakeley C: Revisiting the circulation time of Plasmodium falciparum gametocytes: molecular detection methods to estimate the duration of gametocyte carriage and the effect of gametocytocidal drugs. Malar J 2010, 9:136.

35. White NJ, Pongtavornpinyo W, Maude RJ, Saralamba S, Aguas R, Stepniewska K, Lee SJ, Dondorp AM, White L, Day NPJ: Hyperparasitaemia and low dosing are an important source of anti-malarial drug resistance. Malar J 2009, 8:253.

36. Okell LC, Drakeley CJ, Ghani AC, Bousema T, Sutherland CJ: Reduction of transmission from malaria patients by artemisinin combination therapies: a pooled analysis of six randomized trials. Malar J 2008, 7:125.

37. Targett G, Drakeley C, Jawara M, von Seidlein L, Coleman R, Deen J, Pinder M, Doherty T, Sutherland C, Walraven G, Milligan P: Artesunate reduces but does not prevent post treatment transmission of Plasmodium falciparum to Anopheles gambiae. J Infect Dis 2001, 183:1254-1259.

38. Michael OS, Gbotosho GO, Folarin OA, Okuboyejo T, Sowunmi A, Oduola AM, Happi CT: Early variations in plasmodium falciparum dynamics in Nigerian children after treatment with two artemisinin-based combinations: implications on delayed parasite clearance. Malar J 2010, 9:335.

doi:10.1186/1475-2875-12-60

Cite this article as: Joseph et al:: Exploration of in vivo efficacy of artemether-lumefantrine against uncomplicated Plasmodium falciparum malaria in under fives in Tabora region, Tanzania. Malaria Journal 2013 12:60.

\section{Submit your next manuscript to BioMed Central and take full advantage of:}

- Convenient online submission

- Thorough peer review

- No space constraints or color figure charges

- Immediate publication on acceptance

- Inclusion in PubMed, CAS, Scopus and Google Scholar

- Research which is freely available for redistribution
C Biomed Central 